\title{
Weber Number Tests in the NASA Icing Research Tunnel
}

\author{
Michael C. King ${ }^{1}$ \\ NASA Glenn Research Center, Cleveland, Ohio, 44135 \\ William D. Bachalo \\ Artium Technologies, Inc., Sunnyvale, CA, 94085 \\ Dwayne Bell ${ }^{3}$ \\ McKinley Climatic Laboratory, Eglin Air Force Base, FL, 32542 \\ and \\ Laura E. King-Steen ${ }^{4}$ \\ HX5 Sierra, Cleveland, OH, 44135
}

\begin{abstract}
A study of the Weber Number effects on droplets in the NASA Icing Research Tunnel is described. The work focuses on examining the droplet Weber Number effects observed for droplets accelerated by air flow in the contraction section of the Icing Research Tunnel to the test section. These results will aid in Supercooled Large Drop facility design studies. Measurements acquired with the Phase Doppler Interferometer and High Speed Imaging Dual Range Flight Probes at a series of locations through the contraction are presented alongside a 1D numerical model developed during this study to aid interpretation of the experimental results. An estimate of the maximum Weber Number observed in the Icing Research Tunnel for varying drop sizes up to $1000 \mu \mathrm{m}$ is presented and provided for incorporation into future design studies. Finally, experimental results coupled with a numerical model indicate that breakup of drops up to $1000 \mu \mathrm{m}$ is not occurring in the NASA Icing Research Tunnel up to $129 \mathrm{~m} / \mathrm{s}$.
\end{abstract}

\section{Nomenclature}

$\begin{array}{ll}C D P & =\text { Cloud Droplet Probe } \\ H S I & =\text { High Speed Imaging } \\ I R T & =\text { NASA Icing Research Tunnel } \\ O A P & =\text { Optical Array Probe } \\ P D I & =\text { Phase Doppler Interferometer } \\ P S D & =\text { Particle Size Distribution } \\ S L D & =\text { Supercooled Large Drop } \\ a & =\text { Local Drop Acceleration } \\ B o & =\text { Bond Number } \\ B o^{\star} & =\text { Modified Bond Number } \\ \Delta p & =\text { Difference between Nozzle Water Pressure and Nozzle Air Pressure } \\ \Delta \rho & =\text { Different between Density of Water and Density of Air } \\ c_{d} & =\text { Drag Coefficient } \\ d_{e} & =\text { Equivalent Spherical Diameter } \\ d_{\max } & =\text { Maximum Drop Diameter } \\ d_{v 0.50} & =50^{\text {th }} \text { Percentile Cumulative Volume Diameter, Median Volumetric Diameter } \\ d_{v 0.99} & =99^{\text {th }} \text { Percentile Cumulative Volume Diameter }\end{array}$

${ }^{1}$ Aerospace Engineer, Icing Branch, 21000 Brookpark Road,

${ }^{2}$ President, 470 Lakeside Drive, Unit C

${ }^{3}$ Chief Climatic Test Section, 802 North 2nd Street

${ }^{4}$ Icing Cloud Calibration Engineer, Test Engineering Services, 21000 Brookpark Road, AIAA Member 


$\begin{array}{ll}p_{\text {air }} & =\text { Nozzle Air Pressure } \\ g & =\text { gravity } \\ \rho_{a} & =\text { Density of Air } \\ \rho_{d} & =\text { Density of Water } \\ u_{a} & =\text { Local Air Speed } \\ u_{d} & =\text { Local Drop Speed } \\ u_{r e l} & =\text { Local Relative Speed between the Air and Drop Speed } \\ u_{T . S .0} & =\text { Air Speed at T.S. } 0 \\ \varphi & =\text { Sphericity } \\ \sigma & =\text { Surface Tension } \\ T_{0} & =\text { Total Temperature } \\ T . S . & =\text { Tunnel Station in meters } \\ W e & =\text { Weber Number }\end{array}$

\section{Introduction}

$\mathrm{T}$

HE Federal Aviation Administration (FAA) released new regulations for aircraft related to supercooled large drop (SLD) icing conditions in 2015. These conditions are outlined in the Code of Federal Regulations Title 14 Aeronautics and Space, Chapter 1, Subchapter C, Part 25, Appendix O. The FAA defined Freezing Rain (FZRA) SLD conditions with drop size distributions that can have median volumetric diameters (MVD), or $d_{v 0.50}$, exceeding 500 $\mu \mathrm{m}$ and maximum drop sizes above $2000 \mu \mathrm{m}$. It is generally acknowledged by the icing community to be difficult, if not impossible, to generate a substantial, uniform cloud with these conditions in current icing facilities. Thus, through the sponsorship of the Aeronautics Evaluation and Test Capabilities (AETC) Project of the Advanced Air Vehicles Program (AAVP), NASA has been studying technology that could impact the design of facilities to potentially enable simulation of these large drop conditions.

One technology for SLD that NASA has been studying is related to Weber Number, We, a similarity parameter that relates the inertia of a drop to its surface tension. It is generally held that the Weber Number, $W e$, should be limited in an icing facility design to a range of 12 to 15 through the tunnel contraction to ensure drops do not excessively deform, leading to drop breakup. If this assumption is used, delivery of a cloud of spherical drops the tunnel test section with a $d_{\max }$ of $1000 \mu \mathrm{m}$ and marginal speed and temperature deficits with the surrounding air flow point towards very tall, vertical facility designs. These tall, vertical facilities would likely be height and cost prohibitive. However, some particle size distribution (PSD) data existed that the Icing Research Tunnel (IRT) was delivering large drops to the test section, which contradicts the general theory noted above. As a result, NASA researchers teamed with Artium Technologies, Inc., and the United States Air Force McKinley Climatic Laboratory to investigate the difference between the theoretical calculations and the measured conditions in the IRT, which may then be fed into future design studies that could result in tenable solutions to generating Appendix $\mathrm{O}$ conditions in a controlled environment.

This paper presents particle measurements acquired using the Artium Technologies, Inc. Phase Doppler Interferometer (PDI) and High Speed Imaging (HSI) instruments in the IRT during the Weber Number Test conducted in March of 2017. The results presented herein examine the data acquired from the PDI and HSI instruments, during the test, investigate the deformation of the liquid drops, and determine the Weber Number at several locations through the contraction section of the IRT. The objective of this work is to provide the data necessary for any future SLD facility design studies.

\section{Experimental Description}

The goal of this effort is to provide data that will contribute to the design and development of SLD facilities. Thus, an experiment was specifically designed that would derive the necessary information to determine the Weber Number of drops at varying longitudinal locations, referred to as Tunnel Stations (T.S.) relative to the longitudinal center of the test section, T.S. 0 , for flow through the contraction of the IRT. Both drop size and drop speed are required to determine $W e$. While all drop sizing instruments hardened for use in icing conditions are expected to provide drop size, drop speed is typically not a parameter most instruments can measure. Thus, instruments outside the IRT drop sizing instrument suite were required for this study, which included the Artium Technologies, Inc. PDI and HSI instruments.

\section{A. Instrumentation}

As described in the previous section, PSD data existed indicating that SLD conditions were being delivered to the longitudinal center of the IRT test section, approximately T.S. 0. These data were derived from three drop-sizing 
probes that comprise the IRT drop sizing instrument suite. The IRT instrument suite includes the Droplet Measurement Technologies, Inc. Cloud Droplet Probe (CDP) with a measurement range from 2 to $50 \mu \mathrm{m}$, and the Particle Measurement Systems, Inc. Optical Array Probes, OAP-230X and OAP-230Y, with measurement ranges from 15 to $450 \mu \mathrm{m}$, and 50 to $1500 \mu \mathrm{m}$, respectively [1]. These three probes are required to measure the full range of the particle spectrum. Further information on these probes is available in Ref. [2] through [6].

The Artium Technologies, Inc. PDI is a single particle counter that is also capable of simultaneously measuring particle size and speed, which was critical to this effort. The physical principles underlying the PDI have been well documented in numerous publications, including Ref. [7]. The PDI system splits a laser beam and focuses the two resulting coherent beams to a common point in space, creating an interrogation volume and generating a local interference fringe pattern. Drops passing through this volume will scatter the light, creating a Doppler burst signal as they pass the interference fringe pattern. The PDI measures this Doppler burst with three detectors at separate spatial locations. The resulting phase shift of the Doppler burst signals allows measurement of the spacing of the interference fringe pattern, which is used to determine particle size. The system can size both spherical and quasi-spherical drops. The Dual Range Flight Probe PDI (PDI-FPDR), shown in Fig. 1, has two separate channels, noted as PDI-FPDR-Ch1 and PDI-FPDR-Ch2, allowing the unit to measure the lower (Ch1) and the upper (Ch2) ends of particle size spectrum of a given cloud, simultaneously. During this effort, only the measurements from $\mathrm{Ch} 2$ were examined, which had an approximate range from 15 to $925 \mu \mathrm{m}$, based on the instrument settings. The frequency of the Doppler burst signal is proportional to the speed of the drop based on the instrument setup [8]. Figure 3 shows an example of the drop size to speed correlation acquired with the PDI during this test.

The Artium Technologies, Inc. HSI is another particle sizing instrument, which uses a spatial sampling technique. The HSI acquires high-resolution images of particles passing through the interrogation volume. This volume is created by converging several laser beams on a common spatial point, illuminating particles for image capture by a CMOS camera that is recording at a fixed rate of $300 \mathrm{~Hz}$. The lasers are simultaneously pulsed with a pulse duration on the nanosecond time-scale, reducing motion blur of the images. With knowledge of the system resolution, the system can size spherical and irregularly shaped particles, and quantitative assessments of particle morphology can be made. Similar to the PDI-FPDR, the Dual Range Flight Probe HSI (HSI-FPDR), shown in Fig. 2, has 2 separate channels, allowing the unit to measure the lower (Ch1) and the upper (Ch2) ends of the particle spectrum in a given spray, simultaneously, and like the PDI-FPDR, only the measurements from $\mathrm{Ch} 2$ were examined during this effort. The image size for $\mathrm{Ch} 2$ is 640 pixels by 480 pixels, with a resolution of $9.6 \mu \mathrm{m} /$ pixel. Figure 4 shows example drop images acquired during this test. Ch2 for the HSI-FPDR used for this test had a range from approximately $40 \mu \mathrm{m}$ to over 4 $\mathrm{mm}$. Figure 4 shows example drop images obtained using the HSI-FPDR-Ch2. Note that the air flow is from the left moving towards the right, and the drops are moving towards the right.

Finally, a heated pitot static probe was affixed to the probe mounting plate, allowing for the local airspeed to be determined in addition to the particle size and speed from the HSI-FPDR and PDI-FPDR. This probe can be seen in both Fig. 1 and 2.

\section{B. Rail Mounting}

A $6 \mathrm{~m}$ rail from 80/20 Inc. was mounted to the IRT floor approximately $66 \mathrm{~cm}$ upstream of the longitudinal center of the test section (T.S. 0), even with the leading edge of IRT Model Mounting Plate, allowing the HSI-FPDR and PDI-FPDR interrogation volumes to be positioned at varying T.S. in the contraction up to $7.1 \mathrm{~m}$ (T.S. -7.1) upstream of T.S 0, as shown in Fig. 1 and 2. The rail was raised off the contraction floor with stanchions, which can be seen clearly in Fig. 2, to permit measurement along the centerline of the contraction. The rail was removed and the instruments were mounted to the IRT Model Mounting Plate for measurements made at T.S. 0.

\section{Test Matrix}

During the test, measurements were made with both the PDI and HSI at a range of T.S. and air speeds, where the conditions are defined in Table 1 . The Total Temperature, $T_{0}$, was approximately $-2.5^{\circ} \mathrm{C}$ for all runs. The test focused on a cloud generated with $p_{a i r}=2 \mathrm{psi}$, and $\Delta p=60 \mathrm{psi}$ with the MOD1 nozzles. The spray times in some cases extended to 40 minutes to attempt to capture the full extent of the upper end of the size spectrum with the HSI-FPDR.

\section{Results}

The following subsections present the experimental results. In addition to the experimental results, an explicit, 1D numerical model was developed to simulate drops of varying sizes traversing the IRT contraction at varying air speeds at T.S. 0, uT.S.o, to aid understanding of those results, which is also presented. 


\section{A. Distribution Comparison}

A comparison of the distributions collected by the IRT instrumentation suite and the PDI-FPDR and HSI-FPDR was conducted to understand the differences between the two sets of instruments. As described in the previous section, the test focused on a cloud generated with $p_{a i r}=2 \mathrm{psi}$, and $\Delta p=60 \mathrm{psi}$ with the MOD1 nozzles. Based on the IRT drop sizing instrumentation suite, these conditions generate a cloud with approximate values for $d_{v 0.50}$ of $450 \mu \mathrm{m}$ and $d_{v 0.99}$ of $1050 \mu \mathrm{m}$ when $u_{\text {T.S. }}$ was set to $67 \mathrm{~ms} / \mathrm{s}$ (130 knots). Figures 5 and 6 show the Number Density and Binned Liquid Water Content (LWC) comparison between the IRT CDP, OAP-230X and OAP-230Y and the test PDI-FPDRCh2 and HSI-FPDR-Ch2, respectively. These figures show the size-binned distributions of counts, Fig. 5, and mass, Fig. 6, from each instrument, permitting comparison between instruments with different ranges. The comparison between these instruments through much of the size spectrum is excellent. Ch2 from both the PDI-FPDR and the HSIFPDR have lower limits of approximately $15 \mu \mathrm{m}$ and $40 \mu \mathrm{m}$, respectively. The initiation of roll off at the lower end of the spectrum for the HSI-FPDR is apparent, yet it is also expected based on the image resolution. On the upper end of the spectrum, both the PDI-FPDR and HSI-FPDR roll off sooner than the OAP-230Y. This is possibly an effect of the relative size of the interrogation volumes between the instruments and the number densities at the upper end of the size spectrum, where the quantity of large drops is relatively low. The OAP probes observe drops along the entire exposed beam path between the probe arms whereas the PDI and HSI probes have a more controlled depth of field. The spray durations for the PDI and HSI probes were extended to approximately match the sample volumes between the PDI-FPDR-Ch2 and HSI-FPDR-Ch2 and the OAP-230Y to help compensate for this effect.

\section{B. The HSI and Drop Deformation}

Using the HSI-FPDR allowed for deformation of the drops to be examined during this effort. Figures 7 and 8 show the correlation of the experimental data with the major axis diameter as a function of equivalent spherical diameter, $d_{e}$, where $d_{e}$ is the diameter of a drop with the same volume as the deformed drop. The data presented in these figures were acquired between 6 and $7 \mathrm{~m}$ upstream of T.S. 0 with $u_{\text {T.S. }}$ at $113 \mathrm{~m} / \mathrm{s}(220 \mathrm{knots})$. Surface tension appears to dominate drops below $500 \mu \mathrm{m}$, maintaining a higher degree of sphericity, $\varphi$, the ratio of the surface area of the equivalent spherical drop to the surface area of the deformed drop. Above this range, aerodynamic pressure and shear due to the air to drop relative velocity, $u_{r e l}$, appear to dominate, serving to deform and flatten the drops into oblate spheroids, decreasing $\varphi$.

To simulate the deformation of the drops, a model based on the Bond Number, $B o$, from Ref. [10] was used to correlate the shape of drops to the local T.S. conditions. The model assumes the drops can be represented by halves of two oblate spheroids sharing a common major axis diameter, but having different semi-minor axis lengths. The shape is driven by $B o$, where the classical formulation for $B o$ relates gravitational forces to surface tension, shown below.

$$
B o=\frac{\Delta \rho g d_{e}^{2}}{\sigma}
$$

The model in Ref. [10] was originally developed for rain drops falling in air, accelerated only by gravity. However, based on the similarity between the example provided in Ref. [10] and the images acquired by the HSI-FPDR, such as those shown in Fig. 4, application of the Ref. [10] model to this study's numerical model was attempted. This was accomplished by modifying the classical Bond Number to a modified Bond Number, $B o^{\star}$, where the gravity term, $g$, was replaced with the local drop acceleration, $a$, as shown below. Fig. 7 and 8 demonstrate the agreement between the experimental data and the modified Ref. [10] model. Both the individual drop and bin mean data for the major axis diameter are in much better agreement with the assumption of a deformable drop than the assumption of a spherical drop as drop size increases. This agreement indicates that drop deformation must be accounted for in the numerical simulation of any future SLD facility designs.

$$
B o^{\star}=\frac{\Delta \rho a d_{e}^{2}}{\sigma}
$$

\section{The PDI and Weber Number}

As described in the previous section, the PDI-FPDR is capable of simultaneously measuring the size and speed of each drop. Figure 3 shows the typical characteristic of drop speed as a function of drop size encountered during the test, where the drop speed clearly levels off as drop size increases. Coupling the PDI-FPDR data with the local air speed data derived from the pitot-static probe, the $W e$ can be calculated for each drop.

Figures 9 and 10 show the scatter of $W e$ values for the experimental data measured at the T.S. -7.1 and T.S. -5.8 with $u_{\text {T.S. }}$ at $129 \mathrm{~m} / \mathrm{s}$ ( 250 knots), where a semi-log plot was used to present the data for clarity of the trends. The data 
presented in Fig. 9 and 10 was calculated using the expression shown below for $W e$. The local relative speed, $u_{r e l}$, was calculated using the drop speed, $u_{d}$, from the PDI-FPDR-Ch2 and the air speed, $u_{a}$, from the pitot-static probe.

$$
W e=\frac{\rho_{a} u_{r e l}^{2} d_{e}}{\sigma}
$$

Data from Ref. [11] was used to calculate the drag coefficient, $c_{d}$, for a range of $\varphi$, for numerical model data presented in Fig. 9 and 10. This reference presents data for solid particles with regular shapes, including spheres, octahedrons, tetrahedrons and disks, but not necessarily oblate spheroids. The $c_{d}$ was calculated by interpolating between the data presented in Ref. [11], rather than using the polynomial expressions derived in the reference. The aerodynamic force accelerating the drop was then calculated using $c_{d}$ and the local T.S. conditions via the drag equation, and the dynamics of the drop were calculated through the equations of straight line motion.

As in the previous section, both the individual drop and bin mean data for $W e$ are in much better agreement with deformable drop assumption than the spherical drop assumption as drop size increases. The data appears to diverge from the spherical drop assumption and follow the deformable drop assumption at approximately $400 \mu \mathrm{m}$, leading to much lower $W e$ at drop sizes of $1000 \mu \mathrm{m}$.

\section{Weber Number Model and Comment on Number Density}

Based on the agreement between the experimental and model data sets demonstrated in Fig. 7 through 10, Fig. 11 through 15 were generated to provide insight into the current study. Figure 11 shows the $u_{d}$ and $W e$ profiles for a 1000 $\mu \mathrm{m}$ drop with $u_{\text {T.S. }}$ at $129 \mathrm{~m} / \mathrm{s}$ using both the spherical drop and deformable drop assumptions. The location of the maximum $W e$ is similar for both assumptions, but the profile developed assuming a spherical drop is nearly a factor of three higher than that for the deformable drop assumption with a We of approximately 14. Thus, Fig. 12 and 13 were generated to demonstrate the difference between the $W e$ profiles for varying drop sizes from 100 to $1000 \mu \mathrm{m}$ with the $u_{\text {T.S. }}$ at $129 \mathrm{~m} / \mathrm{s}$. Based on the data presented in Fig. 7 through 10, the deformation of drops should be taken into account for future SLD facility design studies.

The critical We is commonly accepted to be 12 to 15 in the icing community, as described in Ref. [12] and [13], which is typically based on experiments where drops are suddenly exposed to an air jet. Fig. 13, which is based on the deformable drop assumption, indicates that drops above $800 \mu \mathrm{m}$ fall into or above this range with $u_{\text {T.S. }}$ at $129 \mathrm{~m} / \mathrm{s}$. To examine this, Fig. 14 and 15 were generated, where Fig. 14 shows the $u_{d}$ and $W e$ profiles for a $1000 \mu \mathrm{m}$ drop with $u_{\text {T.S. }}$ at $67 \mathrm{~m} / \mathrm{s}$, and Fig. 15 shows the normalized number densities for the PDI-FPDR-Ch2 at $u_{\text {T.S. }}$ at 67, 98 (190 knots) and $129 \mathrm{~m} / \mathrm{s}$ measured at T.S. 0. The data in Fig. 15 has been normalized by the total Number Density for each respective $u_{\text {T.S. }}$ cloud. The distributions were normalized because the magnitudes in each size bin are expected to vary with $u_{\text {T.S. }}$ as the sample volume is a function of air speed, but the relative proportions of each bin should not unless other effects are being manifested. Fig. 14 indicates that the maximum $W e$ at $u_{\text {T.S. }}$ at $67 \mathrm{~m} / \mathrm{s}$ does not exceed a value of eight with the deformable drop assumption, well below the critical We from literature, and it has already been shown in Fig. 13 that drops above $800 \mu \mathrm{m}$ fall into and above the critical $W e$ range defined in literature. However, Fig. 15 demonstrates that there is no apparent statistically significant difference in the distributions between $u$ T.S. 0 at 67,98 and $129 \mathrm{~m} / \mathrm{s}$, which would be the progressive transition from a subcritical to a critical $W e$ range. The proportion of drops towards the lower end of the size spectrum would be expected to increase with increasing $u$ т.S. if a critical threshold leading to drop breakup had been crossed, but Fig. 15 does not indicate that this is occurring. Experimental studies like that described in Ref. [14] demonstrate that drop breakup events result in log-normal drop distributions with size spectrums that can extend up to approximately $10 \%$ of the parent drop diameter. Such a distribution would contain several thousands of drops that should, at the very least, affect the $u$ T.S. 0 at $129 \mathrm{~m} / \mathrm{s}$ distribution shown in Fig. 15 by a noticeable increase the lower bins, but the data simply does not indicate that this is occurring in the IRT. Generally speaking, the results of this work could impact future SLD facility designs, potentially leading to designs that are not height or cost prohibitive.

\section{Summary and Conclusions}

NASA has completed the first Weber Number test in the IRT. The Artium Technologies, Inc. PDI-FPDR and HSIFPDR were successfully used to measure an SLD icing cloud at various stations through the IRT contraction section at varying air speeds. The data acquired by the PDI-FPDR and HSI-FPDR includes PSD, speed and morphology information that can be used to aid future SLD facility design studies. In addition to acquisition of the experimental data, an explicit, 1D numerical model was developed to support the interpretation of the experimental results. The numerical model, which accounts for the drop deformation, and the experimental results are in good agreement. This 
agreement indicates that drop deformation must be accounted for in the numerical simulation of any future SLD facility designs. Utilizing the available experimental and model data, an estimate for the value for the maximum $W e$ for a $1000 \mu \mathrm{m}$ drop with $u_{\text {T.S. }}$ of $129 \mathrm{~m} / \mathrm{s}$ observed in the IRT is approximately 14. Finally, experimental results coupled with the numerical model indicate that there is a very low probability, if any, for breakup of drops up to approximately $1000 \mu \mathrm{m}$ at air speeds up to $129 \mathrm{~m} / \mathrm{s}$ in the IRT. The outcome of this work could impact the assumptions used to design SLD facilities, potentially opening the door to future SLD facility designs that may not be height or cost prohibitive.

\section{Acknowledgements}

The authors wish to acknowledge the financial support for this work by the Aeronautics Evaluation and Test Capabilities (AETC) Project under NASA's Advanced Air Vehicles Program (AAVP). Special thanks are extended to the IRT Technician Staff for their professionalism during the test. Finally, the authors would like to thank Andy Broeren for the expertise he provided during development of this study's numerical model, Mark Potapczuk for supporting this work, and John Oldenburg for providing his insight and expertise.

\section{References}

${ }^{1}$ Steen, L. E., Ide, R. F., Van Zante, J. F., and Acosta, W. J., "NASA Glenn Icing Research Tunnel: 2014 and 2015 Cloud Calibration Procedures and Results," NASA/TM-2015-218758, 2015.

${ }^{2}$ Lance, S., Brock, C. A., Rogers, D., and Gordon, J. A., "Water Droplet Calibration of the Cloud Droplet Probe (CDP) and InFlight Performance in liquid, Ice and Mixed-Phase Clouds During ARCPAC," Atmospheric Measurement Techniques, Volume 3, 2010.

${ }^{3}$ Lance, S., "Coincidence Errors in a Cloud Droplet Probe (CDP) and a Cloud and Aerosol Spectrometer (CAS), and the Improved Performance of a Modified CDP," Atmospheric and Oceanic Technology, Volume 29, 2012.

${ }^{4}$ Droplete Measurement Technologies, Inc., "Cloud Droplet Probe Manual," Boulder, CO: Droplet Measurement Technologies, Inc., DOC-0343, Rev. A, 2013.

${ }^{5}$ Oldenburg, J. R., and Ide, R. F., "Comparison of Drop Size Distributions from Two Drop Sizing Instruments," NASA-TM$102520,1995$.

${ }^{6}$ Hovenac, E. A., "Droplet Sizing Instrumentation Used for Icing Research: Operation, Calibration, and Accuracy," NASACR-182293, 1989.

${ }^{7}$ Albrecht, H.-E., Damaschke, N., Borys, M., and Tropea, C., Laser Doppler and Phase Doppler Measurement Techniques, Springer-Verlag, Berlin, 2003.

${ }^{8}$ Artium Technologies, Inc., "PDI Flight Probe, Dual Range (FPDR) User Manual," Sunnyvale, CA: Artium Technologies, Inc.

${ }^{9}$ Soeder, R. H., Sheldon, D. W., Ide, R. F., Spera, D. A., and Andracchio, C. R., "NASA Glenn Icing Research Tunnel User Manual," NASA/TM-2003-212004, 2003.

${ }^{10}$ Clift, R., Grace, J. R., and Weber, M. E., Bubbles, Drops and Particles, Dover Publications, Inc., Mineola, 2005.

${ }^{11}$ Salman, A. D., and Verba, A., "New Approximate Equations to Estimate the Drag Coefficient of Different Particles of Regular Shape," Periodica Polytechnica of the Technical University Budapest - Chemical Engineering, Vol. 32,1988.

${ }^{12}$ Majithia, A. K., Hall, S., Harper, L., and Bowen, P. J., "Droplet Breakup Quantification and Processes in Constant and Pulse Air Flows," ILASS, ILASS08-4-4, 2008.

${ }^{13}$ Duan, R., Koshizuka, S., and Oka, Y., "Numerical and Theoretical Investigation of Effect of Density Ratio on the Critical Weber Number of Droplet Breakup," Journal of Nuclear Science and Technology, Vol. 40, 2003.

${ }^{14}$ Jain, M., Prakash, R. S., Tomar, G., and Ravikrishna, R. V., "Secondary Breakup of a Drop at Moderate Weber Numbers," Proc. R. Soc. A, 471: 20140930, 2015.

${ }^{15}$ Vargas, M., Sor, S., and Magariño, A. G., "Mechanism of Water Droplet Breakup near the Leading Edge of an Airfoil", 4th AIAA Atmospheric and Space Environments Conference, AIAA-2012-3129, 2012. 
Table 1. Test Points

\begin{tabular}{|c|c|c|c|}
\hline Set & $u_{\text {T.S. }}$ & $\begin{array}{c}\text { PDI-FPDR } \\
\text { T.S. }\end{array}$ & $\begin{array}{c}H S I-F P D R \\
\text { T.S. }\end{array}$ \\
\hline--- & $\begin{array}{c}\mathrm{m} / \mathrm{s} \\
(\text { knots) }\end{array}$ & $m$ & $m$ \\
\hline 1 & $\begin{array}{c}67 \\
(130)\end{array}$ & $\begin{array}{c}0 \\
-5.8 \\
-6.4 \\
-7.1\end{array}$ & $\begin{array}{c}0 \\
-5.6 \\
-6.2 \\
-6.9\end{array}$ \\
\hline 2 & $\begin{array}{c}82 \\
(160)\end{array}$ & $\begin{array}{c}-- \\
-5.8 \\
--- \\
-7.1\end{array}$ & $\begin{array}{c}-3.2 \\
--- \\
-6.2 \\
-6.9\end{array}$ \\
\hline 3 & $\begin{array}{c}98 \\
(190)\end{array}$ & $\begin{array}{c}0 \\
-5.8 \\
-6.4 \\
-7.1\end{array}$ & $\begin{array}{c}0 \\
--- \\
-6.2 \\
-6.9\end{array}$ \\
\hline 4 & $\begin{array}{c}113 \\
(220)\end{array}$ & $\begin{array}{c}0 \\
-5.8 \\
-6.4 \\
-7.1\end{array}$ & $\begin{array}{c}--- \\
--- \\
-6.2 \\
-6.9\end{array}$ \\
\hline 5 & $\begin{array}{c}129 \\
(250)\end{array}$ & $\begin{array}{c}0 \\
-5.8 \\
0 \\
-7.1\end{array}$ & $\begin{array}{c}0 \\
--- \\
-- \\
---\end{array}$ \\
\hline
\end{tabular}




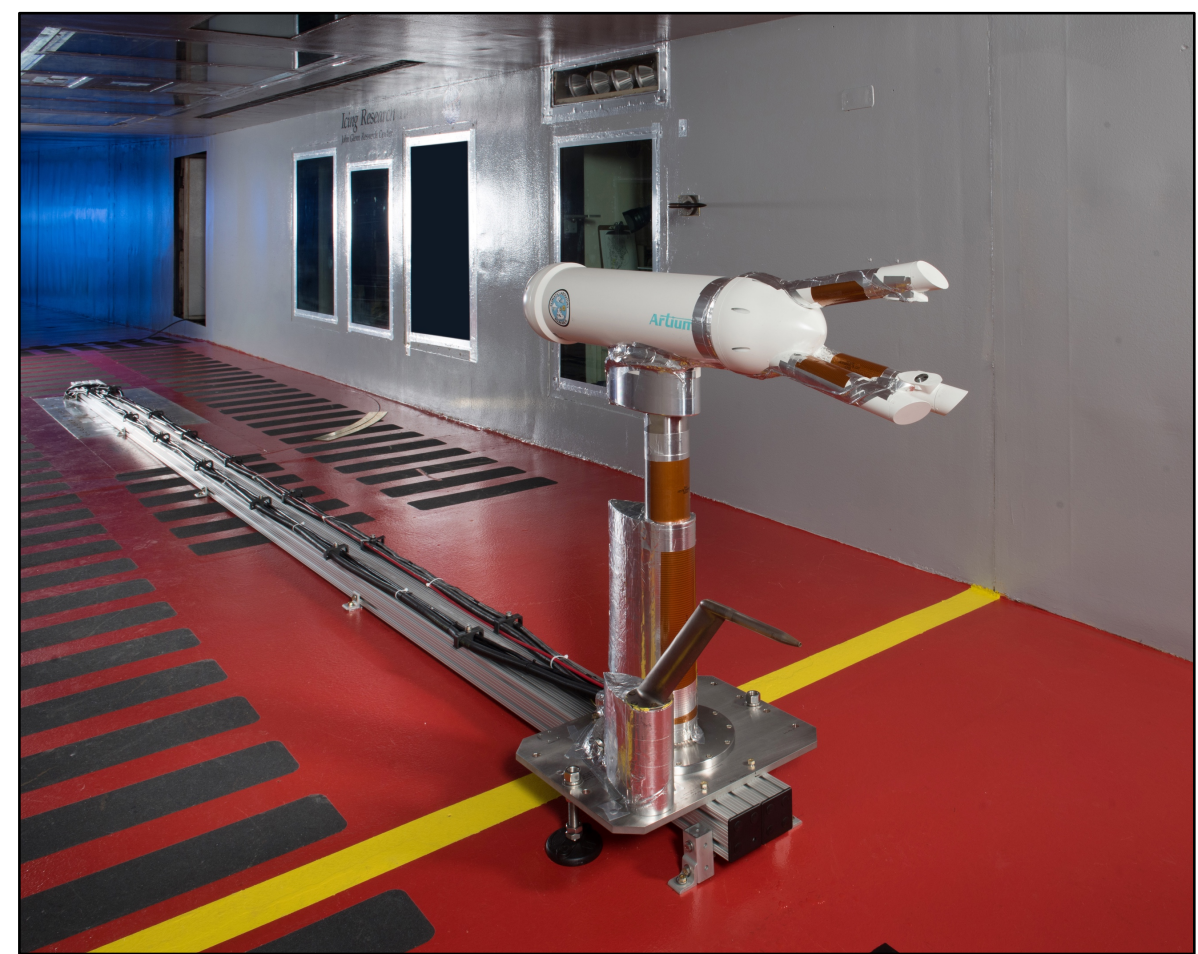

Figure 1. Artium Technologies, Inc. PDI-FPDR and pitot-static probe mounted upstream in the IRT contraction

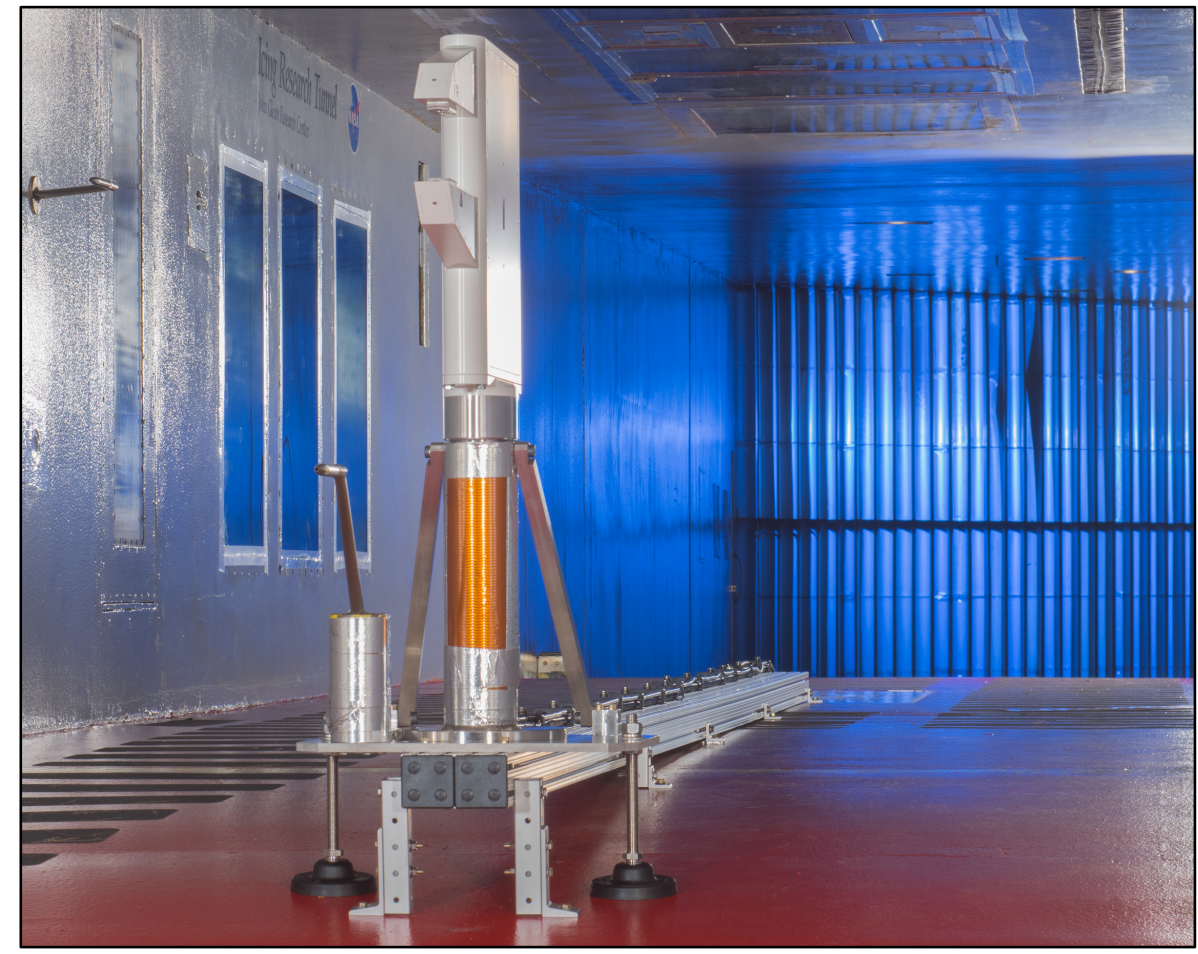

Figure 2. Artium Technologies, Inc. HSI-FPDR and pitot-static probe mounted upstream in the IRT contraction

American Institute of Aeronautics and Astronautics 


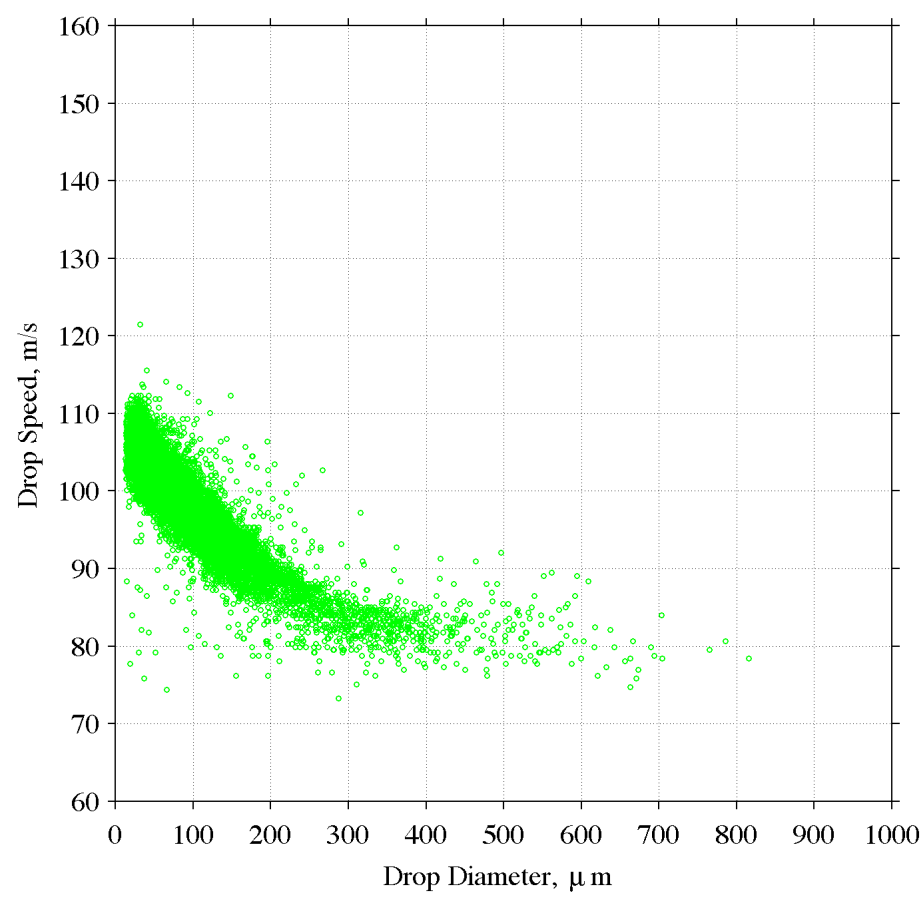

Figure 3. Drop size-speed correlation from PDI-FPDR with $\boldsymbol{u}_{\text {T.S. }}=$ $129 \mathrm{~m} / \mathrm{s}$ (250 knots) measured at T.S. $-\mathbf{5 . 8}$

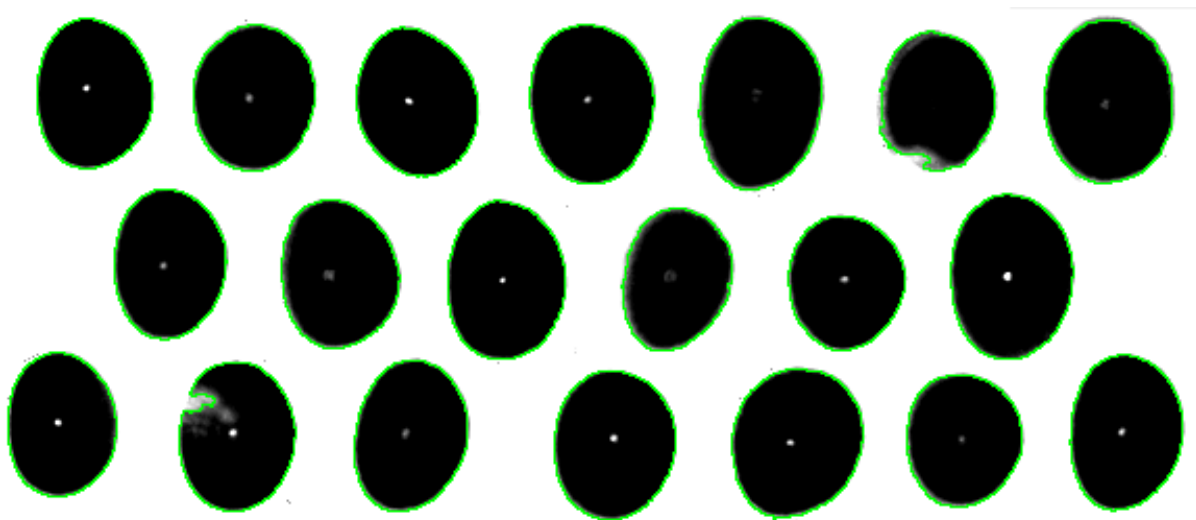

Figure 4. Select drop images from $\mathrm{Ch} 2$ from the HSI-FPDR with $u_{\text {T.S. }}=129 \mathrm{~m} / \mathrm{s}$ (250 knots) measured at T.S. 0 


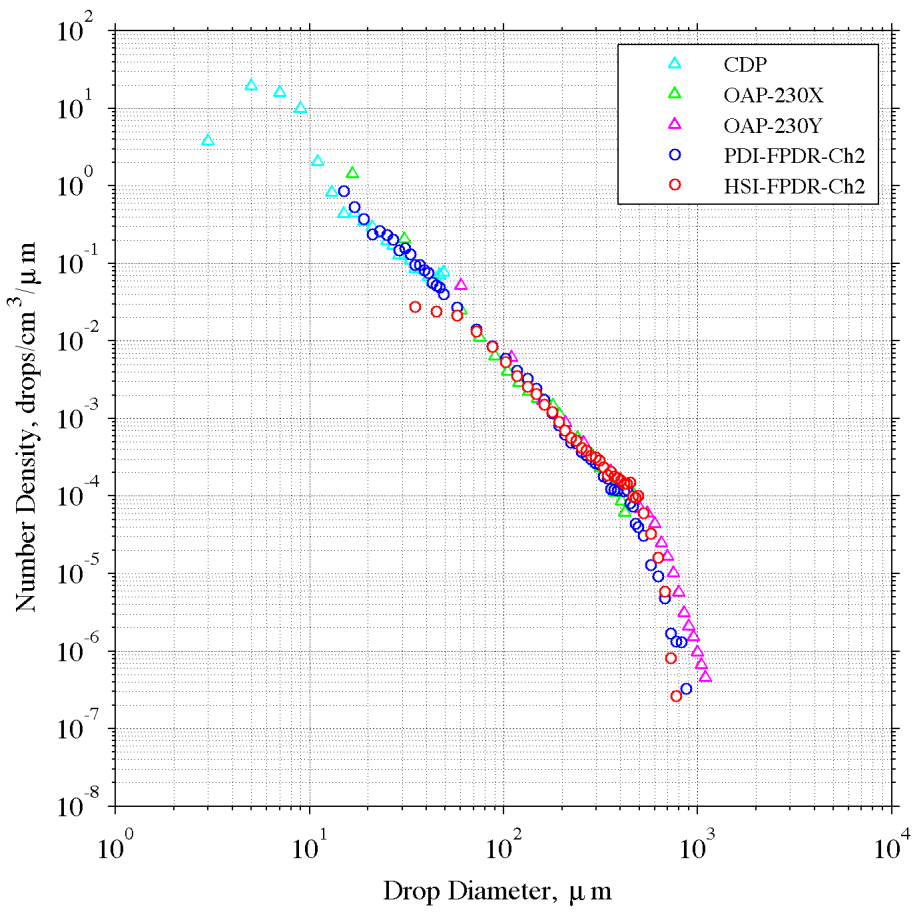

Figure 5. Number densities of the IRT CDP, OAP-230X and OAP$230 Y$, and the test PDI-FPDR and HSI-FPDR with $u_{\text {T.S. } . ~}=129 \mathrm{~m} / \mathrm{s}$ (250 knots), measured at T.S. 0

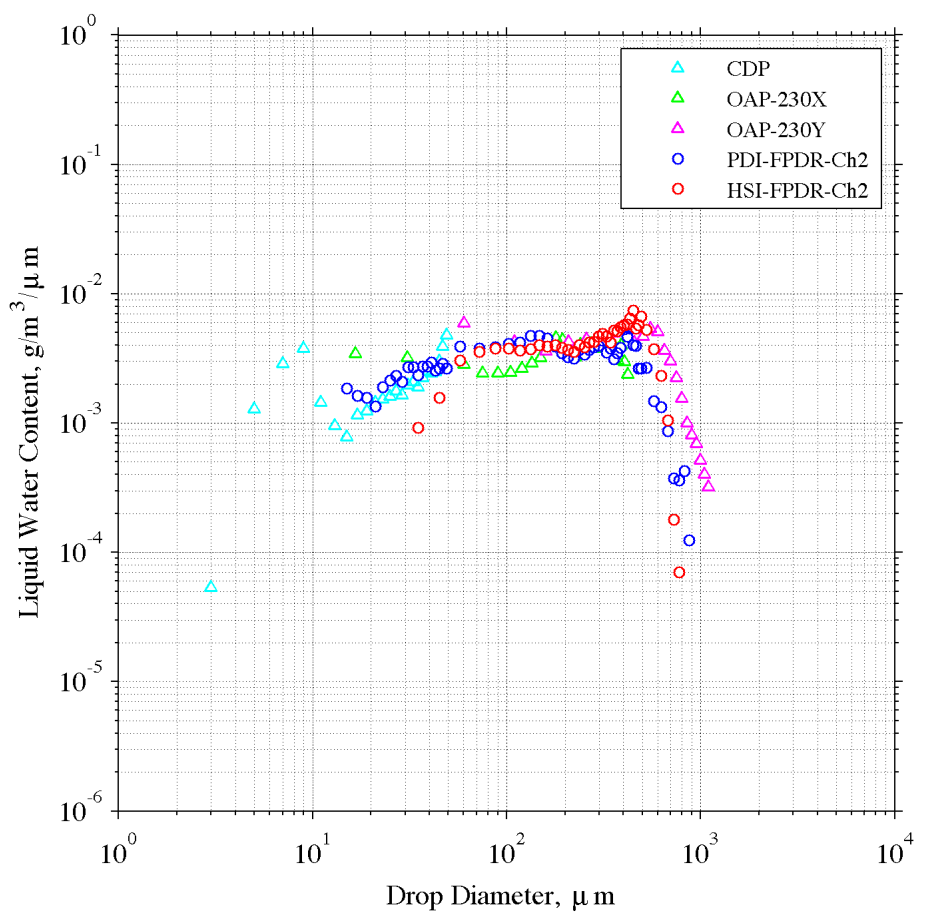

Figure 6. Binned liquid water content comparison between the IRT CDP, OAP-230X and OAP-230Y, and the test PDI-FPDR and HSIFPDR with $u$ T.S. $0=129 \mathrm{~m} / \mathrm{s}(250$ knots $)$ measured at T.S. 0

American Institute of Aeronautics and Astronautics 


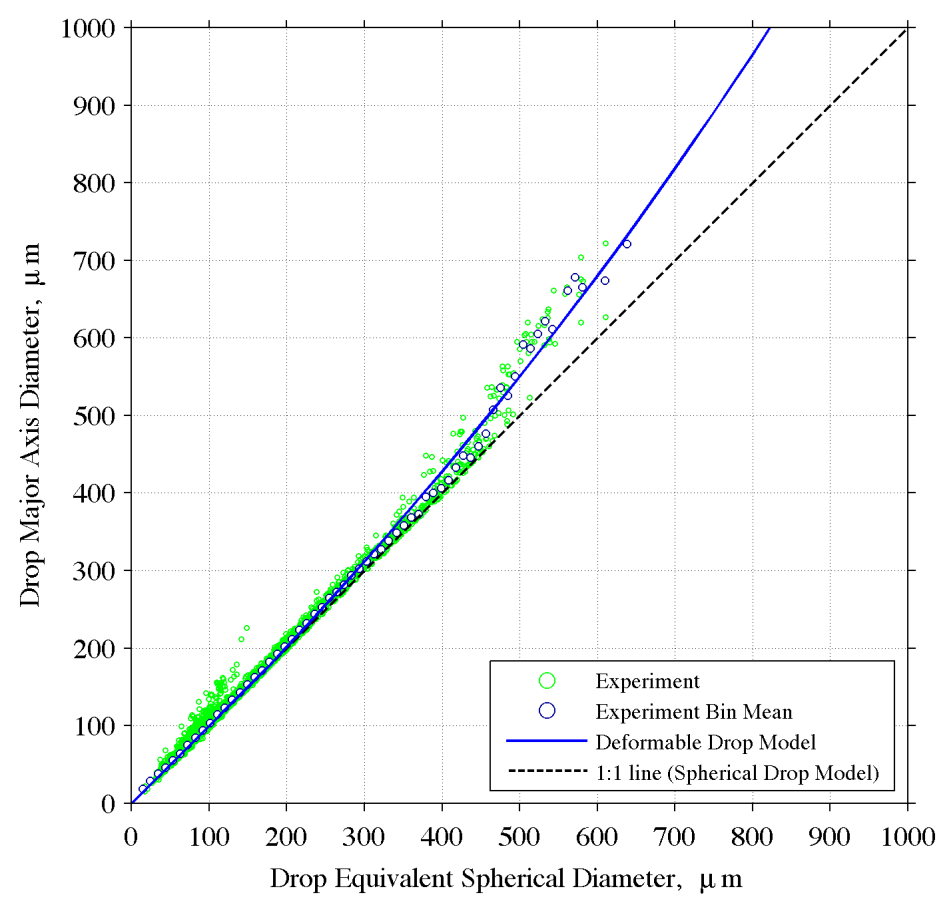

Figure 7. Diameter comparison from HSI-FPDR with $u_{\text {T.S. }}=113 \mathrm{~m} / \mathrm{s}$ (220 knots) measured at T.S. -6.9

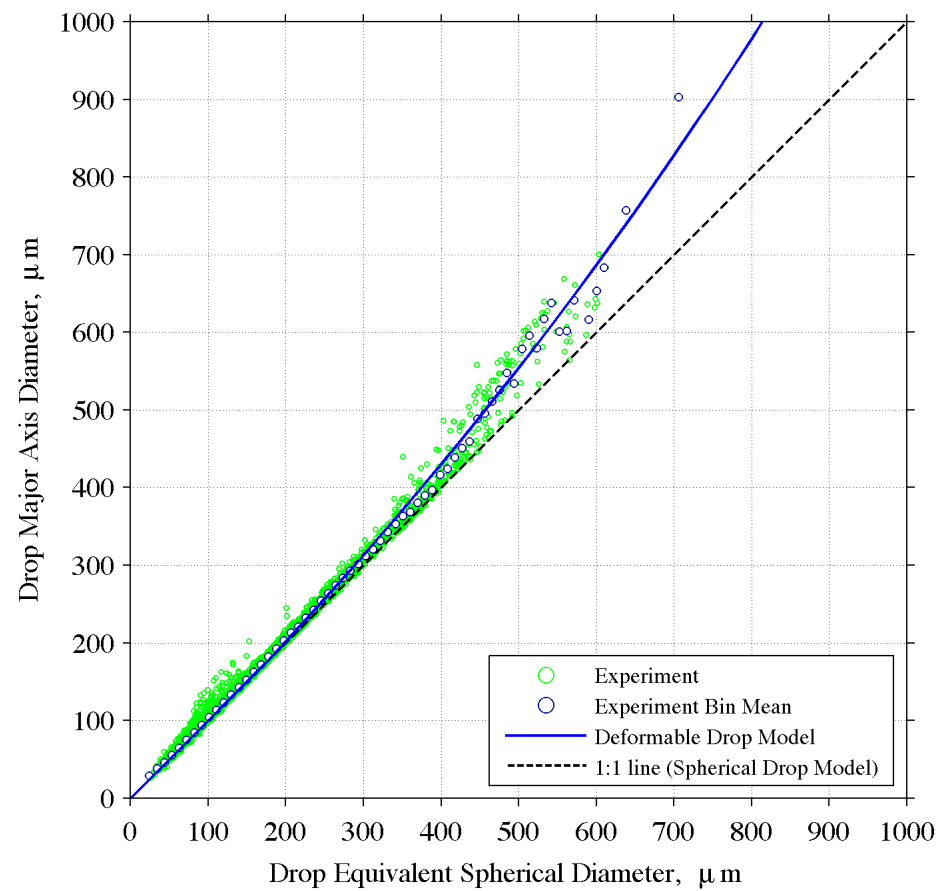

Figure 8. Diameter comparison from HSI-FPDR with $u$ T.S. $0=113 \mathrm{~m} / \mathrm{s}$ (220 knots) measured at T.S. $-\mathbf{6 . 2}$

American Institute of Aeronautics and Astronautics 


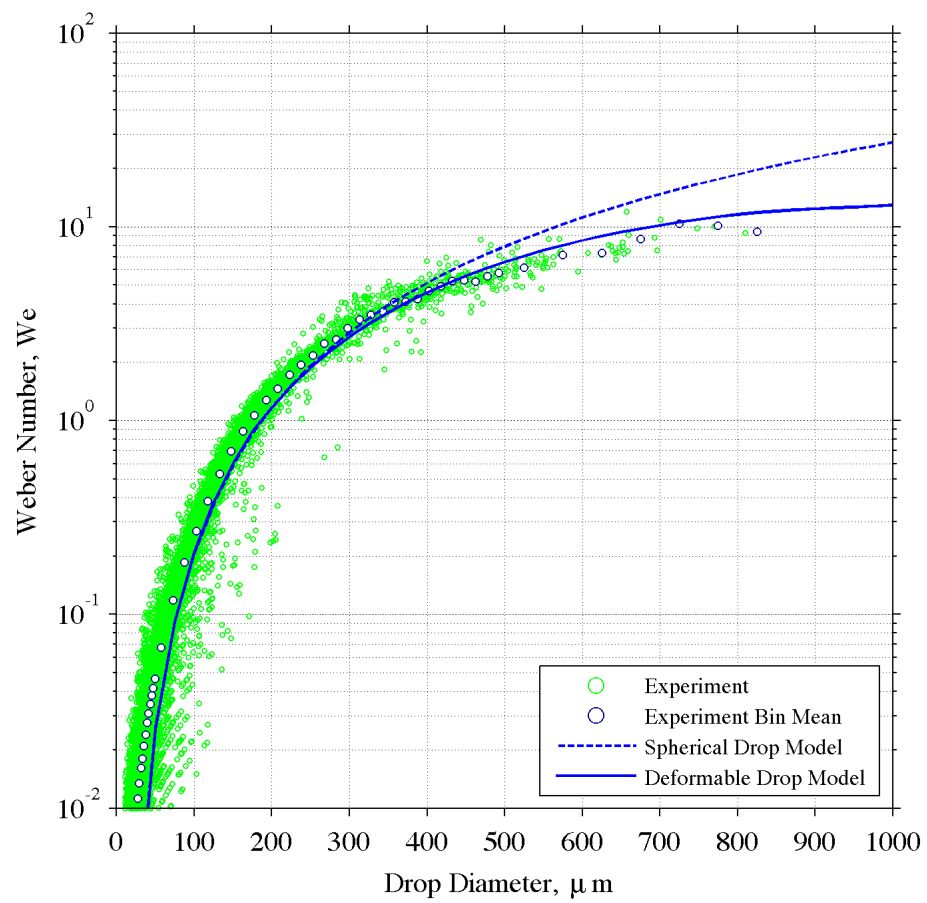

Figure 9. Diameter comparison from PDI-FPDR with $u_{\text {T.S. }}=129 \mathrm{~m} / \mathrm{s}$ (250 knots) measured at T.S. -7.1

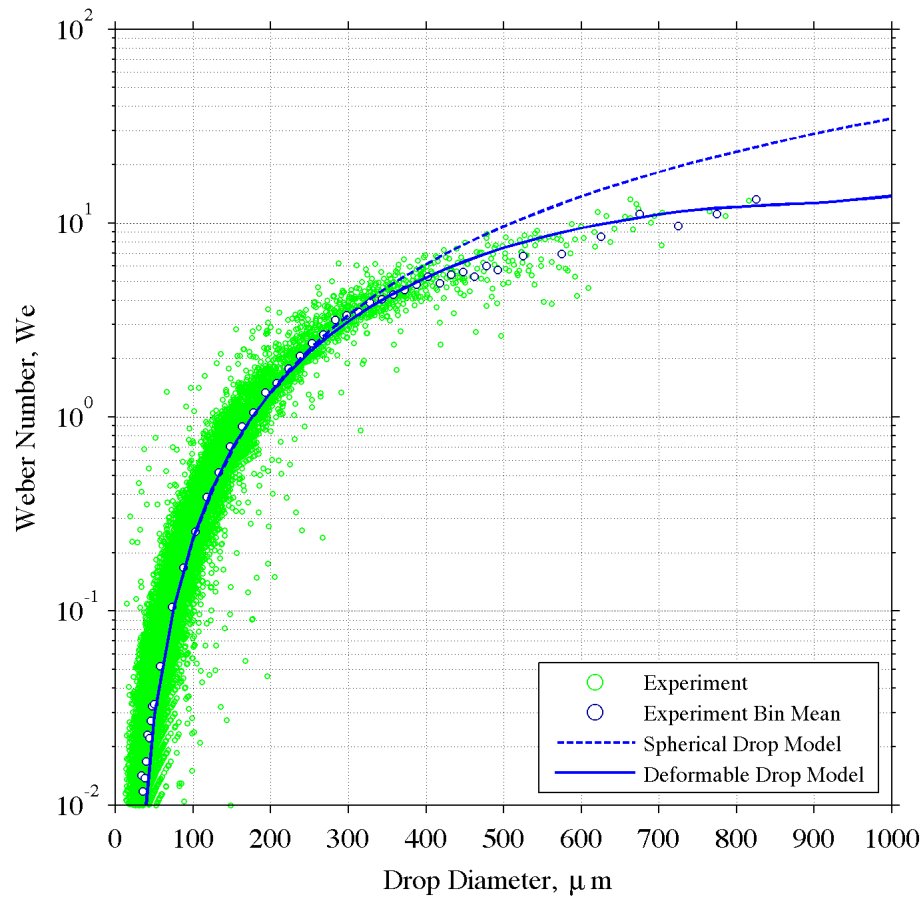

Figure 10. Diameter comparison from PDI-FPDR with $\boldsymbol{u}_{\text {T.S. }}=129$ $\mathrm{m} / \mathrm{s}$ (250 knots) measured at T.S. $-\mathbf{5 . 8}$

American Institute of Aeronautics and Astronautics 


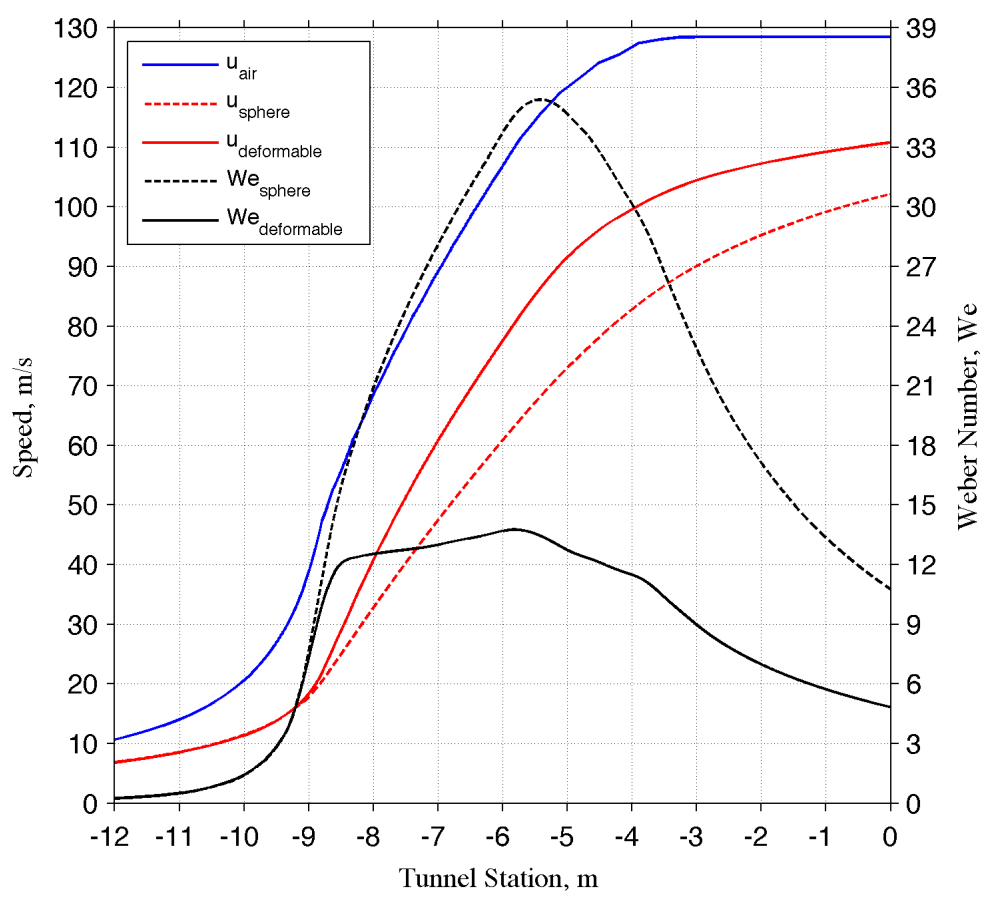

Figure 11. Model generated profiles for $1000 \mu \mathrm{m}$ through IRT contraction with $u_{\text {T.S. }}=129 \mathrm{~m} / \mathrm{s}(250$ knots $)$

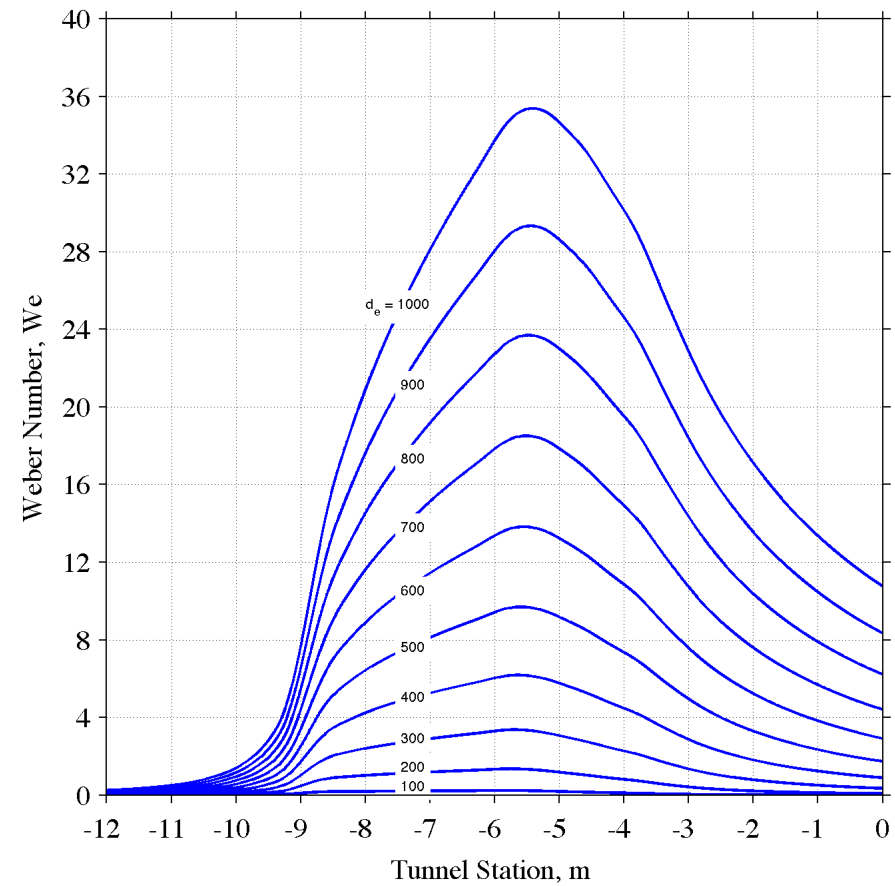

Figure 12. Weber Number, $W e$, at $u_{\text {T.S. }}=129 \mathrm{~m} / \mathrm{s}(250 \mathrm{knots})$ for varying drop equivalent spherical diameters, $d_{e}$, using the spherical

American Institute of Aeronautics and Astronautics 


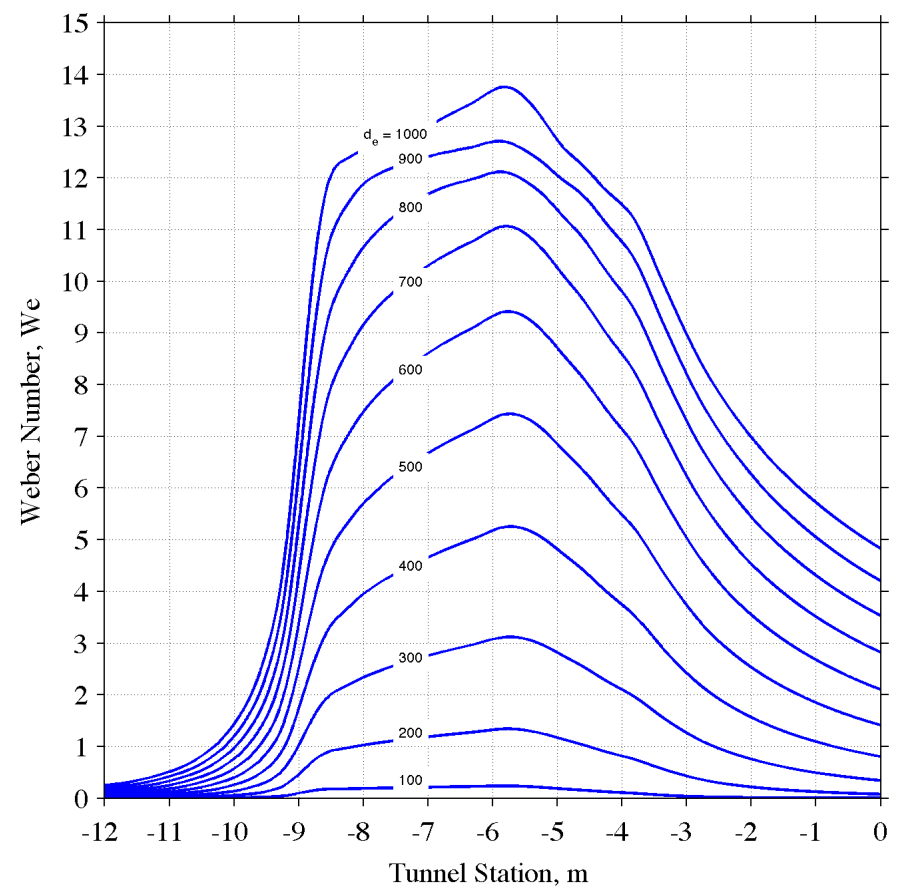

Figure 13. Weber Number, $W e$, at $u_{\text {T.S. }}=129 \mathrm{~m} / \mathrm{s}(250 \mathrm{knots})$ for varying drop equivalent spherical diameters, $d_{e}$, using the

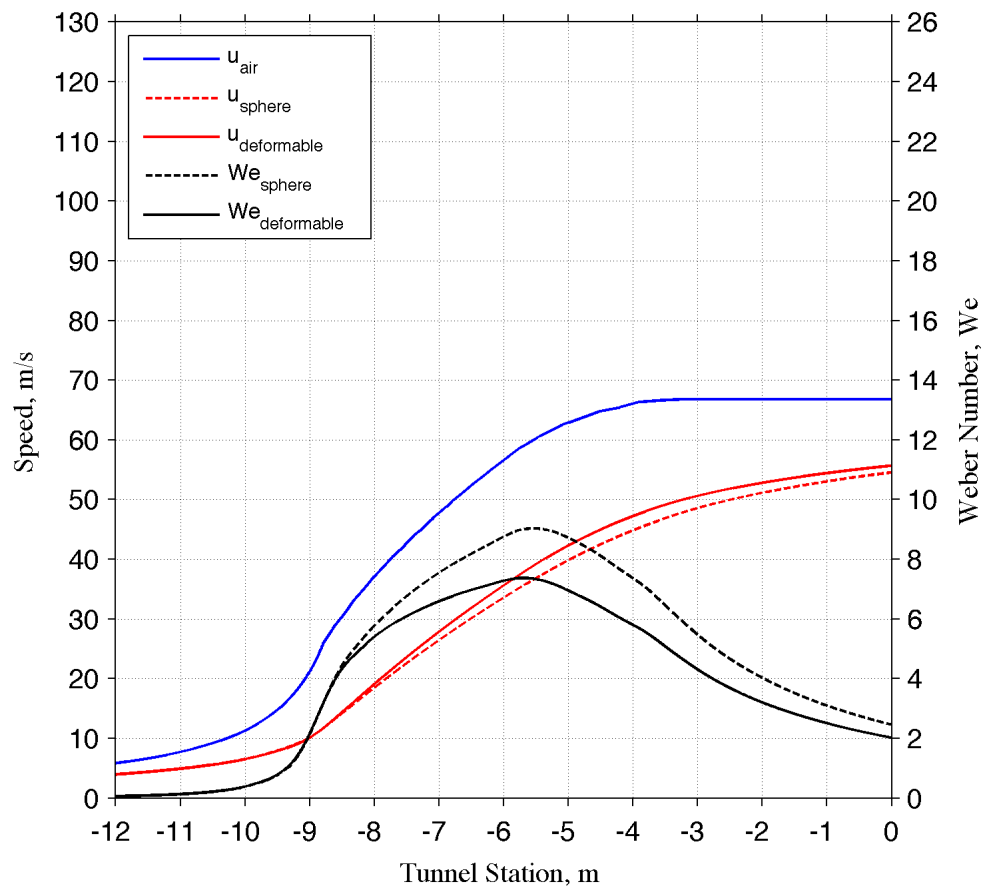

Figure 14. Model generated profiles for $1000 \mu \mathrm{m}$ through IRT contraction with $u$ T.S. $0=67 \mathrm{~m} / \mathrm{s}(130$ knots $)$

American Institute of Aeronautics and Astronautics 


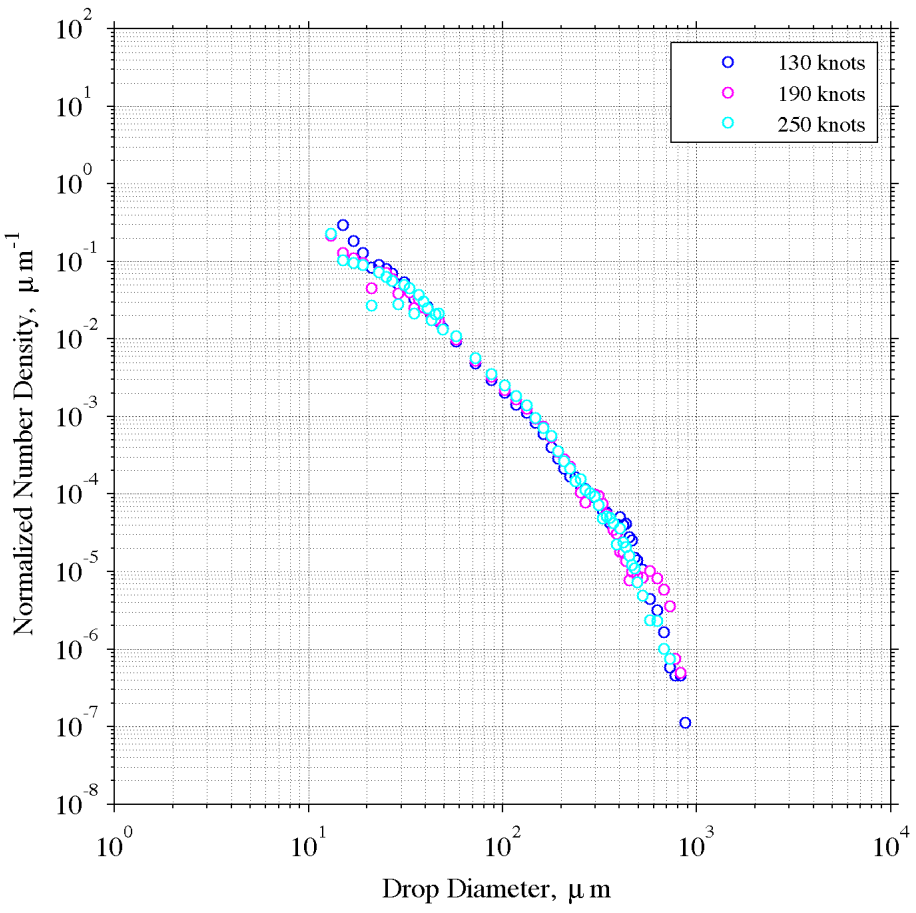

Figure 15. PDI-FPDR-Ch2 normalized number densities measured at T.S. 0 at varying speeds, $u$ T.S. 0 